\title{
Individual differences in brainstem and basal ganglia structure predict postural control and balance loss in young and older adults
}

Citation for published version (APA):

Boisgontier, M. P., Cheval, B., Chalavi, S., van Ruitenbeek, P., Leunissen, I., Levin, O., Nieuwboer, A., \& Swinnen, S. P. (2017). Individual differences in brainstem and basal ganglia structure predict postural control and balance loss in young and older adults. Neurobiology of Aging, 50, 47-59.

https://doi.org/10.1016/j.neurobiolaging.2016.10.024

Document status and date:

Published: 01/02/2017

DOI:

10.1016/j.neurobiolaging.2016.10.024

Document Version:

Publisher's PDF, also known as Version of record

\section{Document license:}

Taverne

Please check the document version of this publication:

- A submitted manuscript is the version of the article upon submission and before peer-review. There can be important differences between the submitted version and the official published version of record.

People interested in the research are advised to contact the author for the final version of the publication, or visit the DOI to the publisher's website.

- The final author version and the galley proof are versions of the publication after peer review.

- The final published version features the final layout of the paper including the volume, issue and page numbers.

Link to publication

\footnotetext{
General rights rights.

- You may freely distribute the URL identifying the publication in the public portal. please follow below link for the End User Agreement:

www.umlib.nl/taverne-license

Take down policy

If you believe that this document breaches copyright please contact us at:

repository@maastrichtuniversity.nl

providing details and we will investigate your claim.
}

Copyright and moral rights for the publications made accessible in the public portal are retained by the authors and/or other copyright owners and it is a condition of accessing publications that users recognise and abide by the legal requirements associated with these

- Users may download and print one copy of any publication from the public portal for the purpose of private study or research.

- You may not further distribute the material or use it for any profit-making activity or commercial gain

If the publication is distributed under the terms of Article $25 \mathrm{fa}$ of the Dutch Copyright Act, indicated by the "Taverne" license above, 


\title{
Individual differences in brainstem and basal ganglia structure predict postural control and balance loss in young and older adults
}

\author{
Matthieu P. Boisgontier ${ }^{\mathrm{a}, *}$, Boris Cheval ${ }^{\mathrm{b}}$, Sima Chalavi ${ }^{\mathrm{a}}$, Peter van Ruitenbeek ${ }^{\mathrm{a}, \mathrm{c}}$, \\ Inge Leunissen ${ }^{\mathrm{a}}$, Oron Levin ${ }^{\mathrm{a}}$, Alice Nieuwboer ${ }^{\mathrm{d}}$, Stephan P. Swinnen ${ }^{\mathrm{a}, \mathrm{e}}$ \\ a Movement Control \& Neuroplasticity Research Group, Department of Kinesiology, KU Leuven, Leuven, Belgium \\ ${ }^{\mathrm{b}}$ Methodology and Data Analysis Research Group, Faculty of Psychology and Educational Sciences (FAPSE), Geneva University, Geneva, Switzerland \\ ${ }^{c}$ Department of Clinical Psychological Science, Faculty of Psychology and Neuroscience, Maastricht University, Maastricht, the Netherlands \\ ${ }^{\mathrm{d}}$ Research Group for Neuromotor Rehabilitation, Department of Rehabilitation Sciences, KU Leuven, Leuven, Belgium \\ ${ }^{\mathrm{e}}$ Leuven Research Institute for Neuroscience E' Disease (LIND), KU Leuven, Leuven, Belgium
}

\section{A R T I C L E I N F O}

\section{Article history:}

Received 15 July 2016

Received in revised form 14 October 2016

Accepted 25 October 2016

Available online 1 November 2016

\section{Keywords:}

Aging

Basal ganglia

Brainstem

Falls

Pedunculopontine nucleus

Posture

\begin{abstract}
A B S T R A C T
It remains unclear which specific brain regions are the most critical for human postural control and balance, and whether they mediate the effect of age. Here, associations between postural performance and corticosubcortical brain regions were examined in young and older adults using multiple structural imaging and linear mixed models. Results showed that of the regions involved in posture, the brainstem was the strongest predictor of postural control and balance: lower brainstem volume predicted larger center of pressure deviation and higher odds of balance loss. Analyses of white and gray matter in the brainstem showed that the pedunculopontine nucleus area appeared to be critical for postural control in both young and older adults. In addition, the brainstem mediated the effect of age on postural control, underscoring the brainstem's fundamental role in aging. Conversely, lower basal ganglia volume predicted better postural performance, suggesting an association between greater neural resources in the basal ganglia and greater movement vigor, resulting in exaggerated postural adjustments. Finally, results showed that practice, shorter height and heavier weight (i.e., higher body mass index), higher total physical activity, and larger ankle active (but not passive) range of motion were predictive of more stable posture, irrespective of age.
\end{abstract}

(c) 2016 Elsevier Inc. All rights reserved.

\section{Introduction}

Falls are a leading cause of injury, affecting all age groups. In 2000, the total cost of fall injuries in the United States was estimated at $\$ 81$ billion (Corso et al., 2015). Compared to younger adults, older adults have higher mortality and hospitalization rates (Kennedy et al., 2001). By 2030, 1 in 5 Americans will be 65 years and older (Colby and Ortman, 2015). Older adults are also becoming healthier and more active, which puts them at risk for similar injuries to those sustained by their younger counterparts, such as non-ground-level falls, associated with a higher burden of injury and mortality (Gelbard et al., 2014). In 2000, the incidence of fatal and nonfatal fall injuries in adults aged over 65 years was estimated at 10,300 and 2.6 million, respectively, for a total cost exceeding \$19 billion (Stevens et al., 2006). Traumatic brain and lower extremity

\footnotetext{
* Corresponding author at: Movement Control \& Neuroplasticity Research Group, Department of Kinesiology, KU Leuven, Tervuursevest 101, 3000 Leuven, Belgium. Tel.: +32 16376471; fax: +32 16329197.

E-mail address: Matthieu.Boisgontier@kuleuven.be (M.P. Boisgontier).
}

injuries were the most frequent injuries, accounting for $78 \%$ of fatalities. The most frequent nonfatal injuries were fractures of the lower and upper extremities (Stevens et al., 2006). In adults aged $65-74$ years, the fatal fall injury rate was $17 \%$, with higher rate for males than females, and the nonfatal fall injury rate was $31 \%$, with higher rate for females than males (Stevens et al., 2006). Accordingly, a better understanding is needed of the neurobiological factors that underlie poor postural control that may result in falls.

Postural control is fundamental for preventing falls, for both young and older adults (Boisgontier et al., 2016a; Heijnen and Rietdyk, 2016). This becomes increasingly critical with aging, especially for prolonging functional independence and preventing the kinds of falls that cause catastrophic injuries (Corso et al., 2015; Gelbard et al., 2014; Kennedy et al., 2001; Stevens et al., 2006; Tinetti and Williams, 1997). Postural control involves a set of mechanisms (e.g., sensory integration, motor command generation, and muscle contraction) that stabilize the center of the total body mass relative to the support base (Shumway-Cook and Woollacott, 2007). Balance is the state of equilibrium resulting from the ability of the postural control system to keep the vertical projection of the 
center of mass within the support base. The better controlled the posture, the less likely that balance will be lost. Recently, wholebrain gray matter structure has been shown to predict both postural control and the odds of balance loss (Boisgontier et al., 2016a). These findings at the whole-brain level concur with evidence that shows or suggests associations between postural performance and many brain regions, encompassing almost the entire brain, including the cerebral cortex (Burciu et al., 2013; Mihara et al., 2008; Slobounov et al., 2005, 2006; Taubert et al., 2016), cerebellum (Drijkoningen et al., 2015; Horak and Diener, 1994; Morton and Bastian, 2004; Ouchi et al., 1999), basal ganglia (Visser and Bloem, 2005), and brainstem (Drijkoningen et al., 2015; Honeycutt et al., 2009; Karachi et al., 2010). However, the relative predictive power of these structures remains unclear. Given the technical difficulty of accurately testing deep brain functional activity in a standing balance task, and given the correlation between brain volume and brain activity (Qing and Gong, 2016), structurebased predictions are needed to improve the understanding of the underlying neural mechanisms of postural control and falls.

Posturography has been widely used to investigate the mechanisms involved in postural control (e.g., Boisgontier et al., 2013). This technique involves measuring the movement of the center of pressure (CoP), which has shown to predict falls in older adults (Pajala et al., 2008). However, it remains unclear whether CoP displacements mediate the effect of age on balance loss events (Boisgontier et al., 2016a). The relative effect of the different brain structures on postural control with aging is also debatable. At the brain level, the impact of aging on synaptic modeling (Bloss et al., 2011) and neuron density (Andersen et al., 2003) varies across brain regions (Boisgontier, 2015), which could explain the varying impact of aging on brain structures (Walhovd et al., 2011; Ziegler et al., 2012). Hence, certain brain structures, such as the brainstem, may account for the relationship between aging and posture better than other regions do.

The objective of this study was to determine which brain regions generally predict human postural control and balance during upright standing, irrespective of static versus dynamic postural conditions, task difficulty, practice, visual condition, joint mobility, physical activity, and age. In sum, we investigated which brain regions are fundamental for postural control and balance. In addition, to determine the extent to which these structures mediate the effect of age on postural control, we examined 10 cortical and subcortical regions of interest (ROIs) that have been associated with posture. We hypothesized that (1) the brainstem is the most critical brain region for postural control and for balance loss prevention and that (2) the brainstem accounts for the age-related decline in postural control. Indeed, the brainstem is essential for posture (Drijkoningen et al., 2015; Honeycutt et al., 2009), owing to its involvement in fast postural responses (Jacobs and Horak, 2007) and startle reflexes (Brown et al., 1991; Nonnekes et al., 2015), which are critical for preventing balance loss. Furthermore, a specific brainstem substructure, the pedunculopontine nucleus, has gained recent attention as a strong predictor of postural stability (Fling et al., 2013; Karachi et al., 2010; Lau et al., 2015; Welter et al., 2015).

\section{Methods}

\subsection{Participants}

Thirty young (age, $22 \pm 3$ years; height, $175 \pm 9 \mathrm{~cm}$; weight, 69 $\pm 12 \mathrm{~kg} ; 16$ males, 14 females) and 28 older ( $70 \pm 5$ years; 169 $\pm 8 \mathrm{~cm} ; 77 \pm 13 \mathrm{~kg} ; 15$ males, 13 females) healthy volunteers participated in this study. All participants had normal or correctedto-normal vision, and none reported a history of neurologic, psychiatric, cardiovascular, or neuromuscular disorders. In addition, a certified physical therapist with extensive experience in neurorehabilitation (MPB) attended all testing sessions and observed no symptoms or indicators suggesting neural disorders. Older participants were screened for cognitive impairment with the Montreal Cognitive Assessment test using the standard cut-off score of 26. The total score on the International Physical Activity Questionnaire (Craig et al., 2003) was used to determine total physical activity. All participants gave their written informed consent, and procedures were performed according to the guidelines of the ethics committee for biomedical research at KU Leuven, Belgium and in accordance with the World Medical Association International Code of Medical Ethics.

\subsection{Postural task}

Standing balance was tested on an Equitest balance platform (Neurocom International, Inc, Clackamas, OR, USA). This dynamic postural system consists of a force platform $(46 \times 46 \mathrm{~cm})$ that moves around a mediolateral axis and is equipped with force transducers to measure $\mathrm{X}, \mathrm{Y}$, and $\mathrm{Z}$ forces (Fx, Fy, and $\mathrm{Fz}$ ) and $\mathrm{X}, \mathrm{Y}$, and $\mathrm{Z}$ moments ( $\mathrm{Mx}, \mathrm{My}$, and $\mathrm{Mz}$ ). Participants stood barefoot, with the medial malleoli of the ankles vertically aligned with the platform's axis of rotation. A safety harness was worn to prevent falls due to loss of balance (hereinafter, balance loss). To fully assess balance performance, 7 balance disturbance conditions with different platform frequencies and mean amplitudes were tested in eyes open and eyes closed conditions (Fig. 1). The $0.0 \mathrm{~Hz}-0.0^{\circ}$ couple (static) was the least challenging condition. The 0.1 $\mathrm{Hz}-5.0^{\circ}$ couple (very slow movement) was the most challenging condition in terms of movement perception. The $0.1+1.5+6.0$ $\mathrm{Hz}-5.0^{\circ}$ couple was the most challenging condition in terms of triggering rapid corrective responses. The 4 remaining couples $\left(0.1 \mathrm{~Hz}-0.7^{\circ}, 1.5 \mathrm{~Hz}-0.7^{\circ}, 1.5 \mathrm{~Hz}-1.3^{\circ}\right.$, and $\left.1.5 \mathrm{~Hz}-2.7^{\circ}\right)$ were used to link the previously mentioned extreme couples: the challenge increased progressively with increasing amplitude and frequency. Each trial lasted 1 minute and was repeated twice, for a total of 28 randomized trials per participant $(7$ patterns $\times 2$ visual conditions $\times 2$ trials). Participants were invited to rest for 10 minutes after the 14th trial. When participants asked for a break at any other time during the test session, they were allowed to rest and they got back onto the platform as soon as they had recovered. Participants were instructed to minimize body sway. When a participant fell (held by the safety harness) or took a step to regain balance, the trial was recorded as a balance loss event and was removed from the CoP analysis. These events were counted and used as an indicator of balance. Participants were given another opportunity to complete the failed trials after performing all 28 trials.

\subsection{Analysis of postural sway}

The amount of CoP movement along the anteroposterior axis was computed using the root mean square deviation of the time series, and was used as an indicator of postural control (CoP root mean square deviation [RMSD]). The CoP coordinates along the anteroposterior axis (CoPy) of the platform surface were computed in $\mathrm{mm}$ as follows:

$\mathrm{CoPy}=\frac{(\mathrm{CoPz})(\mathrm{Fy})-\mathrm{Mx}}{\mathrm{Fz}}$

where $\mathrm{CoPz}$ is the distance from the transducers to the platform surface, Fy is the anteroposterior force, $\mathrm{Mx}$ is the moment about the mediolateral axis, and $\mathrm{Fz}$ is the vertical force. 


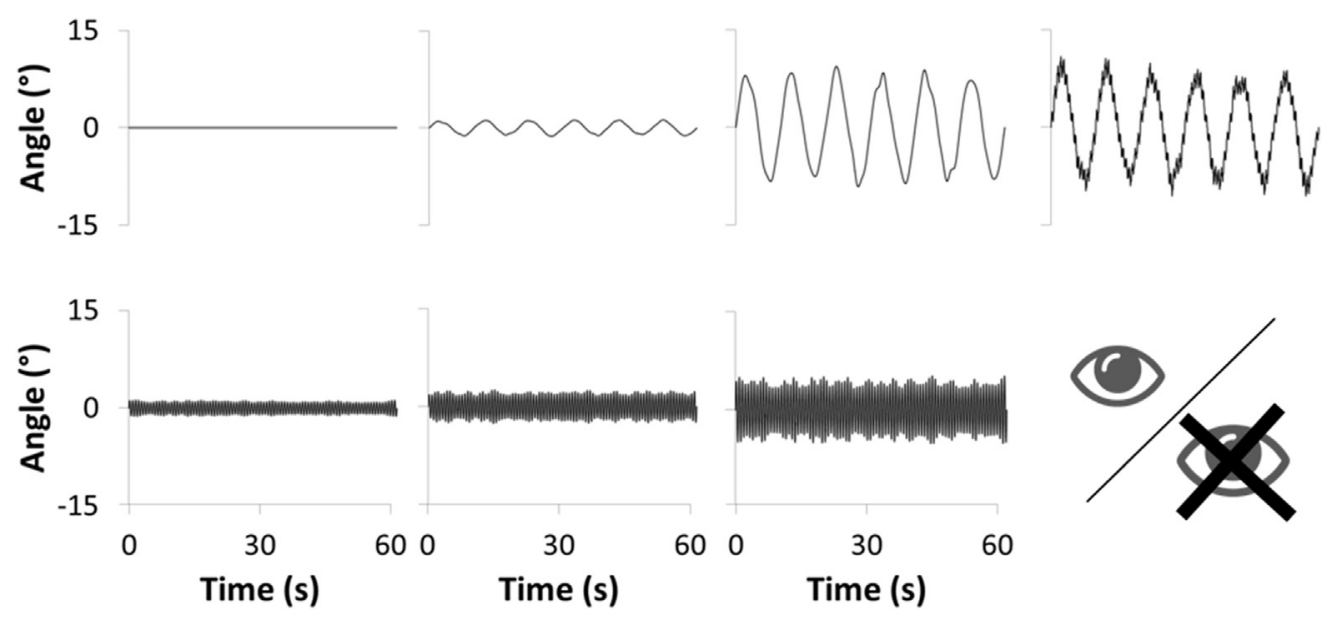

Fig. 1. Balance disturbance patterns used in eyes open and eyes closed condition.

The root mean square deviation (CoP RMSD) of the detrended CoP time series was computed in $\mathrm{mm}$ as follows:

CoP RMSD $=\sqrt{\frac{1}{N} \times \sum_{1}^{N}(\mathrm{CoPy})^{2}}$

where $\mathrm{N}$ is the number of data samples over a trial of 58 seconds $\left(5.8 \times 10^{3}\right)$, with the first 2 seconds of each 1 -minute trial removed from the analysis.

\subsection{Goniometric measurement of passive and active ankle range of motion}

A plastic $360^{\circ}$ goniometer with movable arms (length $=12.7 \mathrm{~cm}$ ) and a scale marked in $1^{\circ}$ increments were used by a single physical therapist tester (MPB) to measure bilateral passive and active ankle range of motion (ROM). The ankle ROM measurement method is outlined in Norkin and White (1995). Briefly, to measure active plantar flexion and dorsiflexion, the participant was seated at the edge of a table, knee flexed, feet unsupported, and was asked to actively assist the movement while the tester maintained proper alignment of movement. Passive plantar flexion was measured in the same position, and passive dorsiflexion was measured in a weight-bearing lunge position (Konor et al., 2012). Intratester reliability of active (Youdas et al., 1993) and passive ROM (Elveru et al., 1988) has demonstrated good reliability. Plantar flexion and dorsiflexion were measured 3 times for each ankle and in each condition (active and passive), for a total of 12 measures per participant ( 3 measures $\times 2$ ankles $\times 2$ conditions). The 3 measures were averaged, and the dorsiflexion and plantar flexion values were summed (total ROM). The lowest total ROM between right and left ankle was used as an indicator of ankle mobility.

\subsection{Structural brain image acquisition}

Brain images were acquired on a 3.0 T Philips Achieva magnetic resonance imaging scanner (Philips Healthcare, Best, the Netherlands) with a 32-channel head coil. For each participant, a high-resolution T1-weighted image was acquired using a magnetization prepared rapid gradient echo (MPRAGE) sequence (repetition time, $9.70 \mathrm{~ms}$; echo time, $4.60 \mathrm{~ms}$; flip angle, $8^{\circ} ; 230$ sagittal slices; voxel resolution, $0.98 \times 0.98 \times 1 \mathrm{~mm}$; matrix, $384 \times 384$ ).

\subsection{Extraction of cortical and subcortical gray matter volumes}

All T1-weighted images were visually inspected in the 3 orthogonal planes using xjView software (http://www.alivelearn. net/xjview) in Matlab R2008a (The MathWorks Inc, Natick, MA, USA), revealing no anatomical abnormalities or magnetic resonance artifacts. Therefore, no participant was excluded at this step. FreeSurfer (V5.0: https://surfer.nmr.mgh.harvard.edu/) was used to extract the volume in $\mathrm{mm}^{3}$ of cortical and subcortical regions. Technical particulars of FreeSurfer have been described in detail by the developers (Fischl and Dale, 2000). Briefly, image processing included motion correction, skull stripping, Talairach transformation, subcortical structure segmentation, intensity normalization, tessellation of the gray matter boundary, and surface deformation following intensity gradients to optimally place the gray/white matter and gray matter/cerebrospinal fluid borders at the location where the greatest shift in intensity defines the transition to the other tissue class. Once the cortical models were completed, a refinement procedure was applied to obtain a representation of the gray matter boundary. This surface was subsequently deformed outward to obtain an explicit representation of the pial surface, which was then divided into distinct cortical regions. The parcelation of cortical surface labeled 34 cortical regions per hemisphere. Cortical volume was computed as the product of thickness and surface area (Panizzon et al., 2009). Each subcortical voxel was assigned to 1 of 39 labels by the automatic subcortical segmentation, after which the volume of each subcortical structure was extracted (Dale et al., 1999; Fischl and Dale, 2000; Fischl et al., 2004). Results of the FreeSurfer automated registration and skull stripping procedure were visually inspected, and all were satisfactory. Left and right parcels were summed to avoid multicollinearity, and the following 10 ROIs were selected: middle frontal gyrus, paracentral lobule, postcentral gyrus, precentral gyrus, superior frontal gyrus, superior parietal gyrus, cerebellum, thalamus, basal ganglia (calculated as the sum of the bilateral caudate, putamen, pallidum, and nucleus accumbens volumes), and brainstem (Fig. 2A). All these regions are of specific interest in the field of postural control and balance, but for different reasons. The dorsolateral prefrontal cortex, which is part of the middle frontal gyrus, has been shown to be involved in the attentional processes associated with balance control (Mihara et al., 2008). The primary somatosensory cortex, which is part of the postcentral gyrus and paracentral lobule, is critical for proprioception, which is required for balance control (Goble et al., 2011, 2012). The primary motor cortex, which is part of the 
A REGIONS of INTEREST
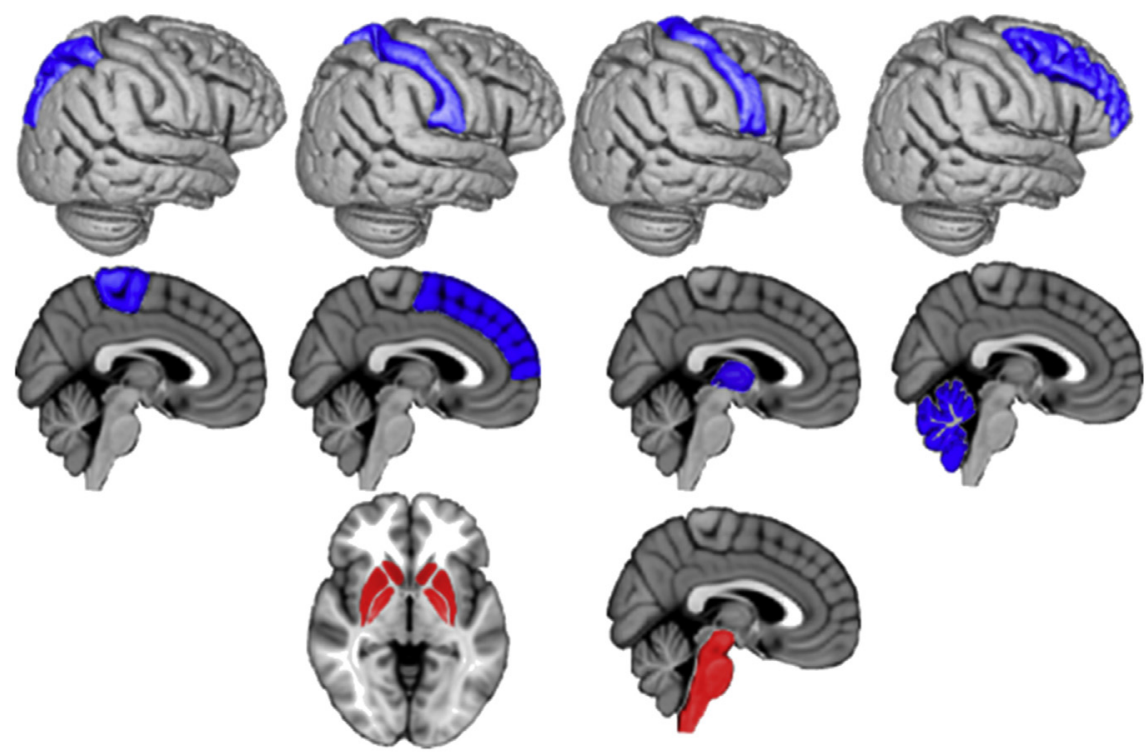

B

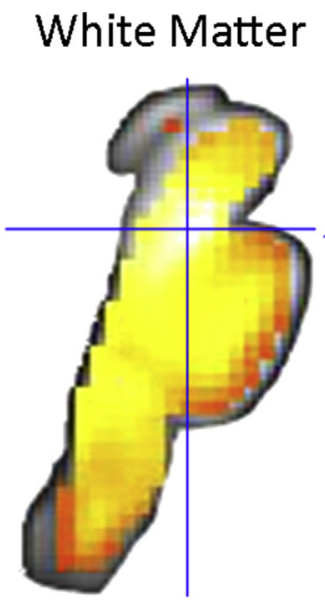

BRAINSTEM

Gray Matter

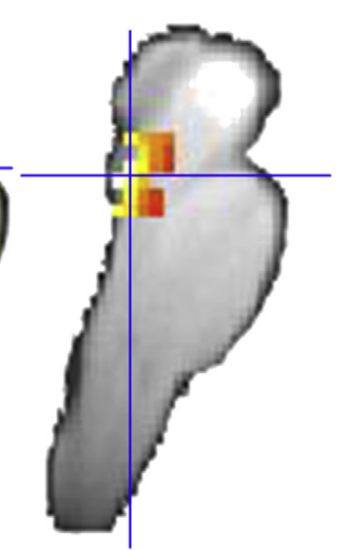

$p=0.05$
C
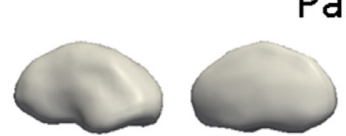

Nucleus Accumbens
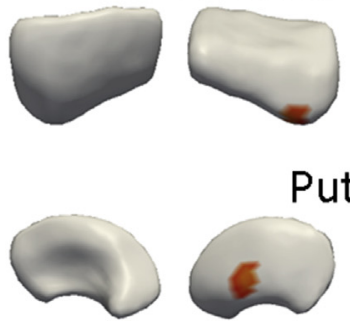

Medial Lateral Left
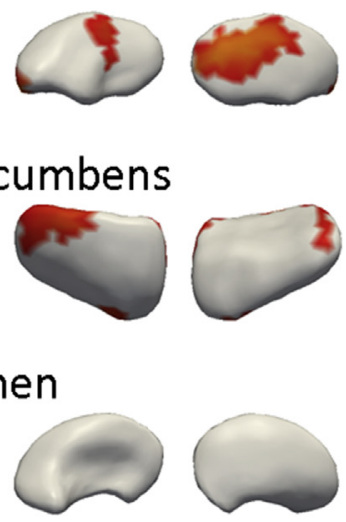

Medial Lateral Right

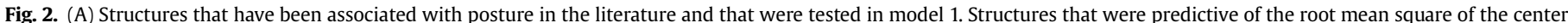

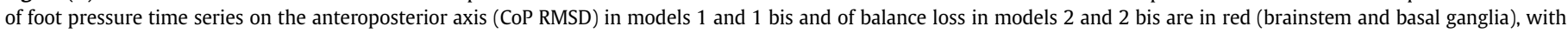

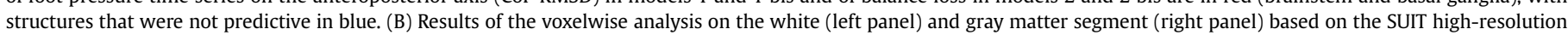

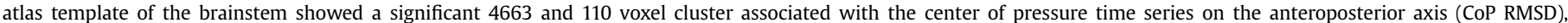

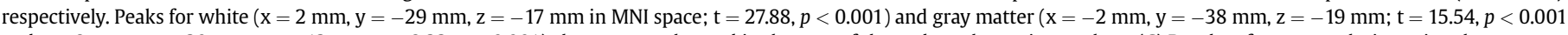

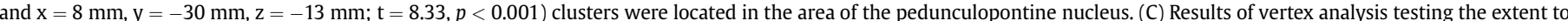

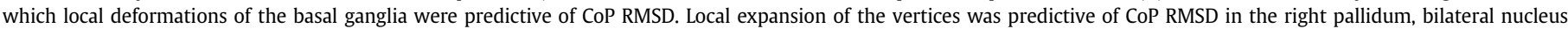

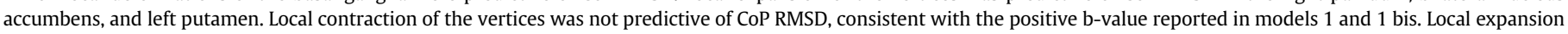

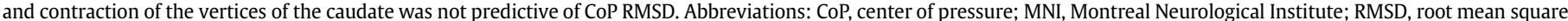
deviation. (For interpretation of the references to color in this figure legend, the reader is referred to the Web version of this article.)

precentral gyrus and paracentral lobule, is responsible for control of the muscles involved in posture and has been shown to be impacted by practice of a postural task (Taubert et al., 2016). The supplementary motor area, which is part of the superior frontal and precentral gyrus, is involved in the preparation of stepping reactions that prevent falls (Mihara et al., 2008). The superior parietal gyrus is involved in the dynamic representation of the body schema (Pellijeff et al., 2006) and body motion (Jellema et al., 2004; Vangeneugden et al., 2011) and in detecting postural instability (Slobounov et al., 2006). The cerebellum is critical for accurately tuning the magnitude of the postural responses (Horak and Diener, 1994). The thalamus is critical for perception of the body's orientation in relation to gravity (Karnath et al., 2000). The basal ganglia adapt the postural responses according to the specificities of the task at hand (Visser and Bloem, 2005). The brainstem is involved in the production of appropriate muscle activation patterns in response to postural disturbances (Honeycutt et al., 2009). 


\subsection{Statistical analysis}

\subsubsection{Center of pressure analysis}

We built our data set with repeated and nested measurements on individual participants and crossed them with each condition. Thus, data were analyzed using linear mixed models with crossed random factors. Linear mixed models take into account the sampling variability of both participants and conditions, thereby preventing a substantial inflation of false positives (i.e., type 1 error), whereas traditional analyses of variance such as analyses of variance disregard this sampling variability (Boisgontier and Cheval, 2016). In light of the recent concerns about false positive rates in imaging studies (Eklund et al., 2016), the addition of such conservative statistical methods to imaging analyses should be promoted. Moreover, treating both participants and conditions as random effects allows generalizing the results not only to the population of participants but to the population of conditions as well. Finally, linear mixed models prevent information loss due to averaging over observations, as the model accounts for all single trials.

Therefore, the extent to which the 10 cortical and subcortical ROIs predicted CoP RMSD was analyzed using a linear mixed model (model 1) with participants $(\mathrm{n}=58)$ and balance disturbance conditions $(\mathrm{n}=7)$ as random factors. This model was built using the $\mathrm{R}$ language lmerTest package, Version 2.0-30 (http://www. r-project.org/). CoP RMSD was normalized using the Box-Cox method (Box and Cox, 1964; Osborne, 2010). The continuous variables were scaled and centered on zero. The following factors were also included: trial (1-28), vision (eyes closed vs. eyes open), weight, height, age (young vs. older adults), and total intracranial volume. The order of trials was included in the model to control for potential practice effects (i.e., fatigue and/or learning effects). This type of control is possible using linear mixed models only, as traditional analyses of variance require averaging trials. Height was also included to control for the impact of a higher center of mass location on postural performance in taller participants (Alonso et al., 2015; Boisgontier et al., 2016a; de Oliveira, 2016). The predictors were checked for the absence of multicollinearity and showed variance inflation factors below 10 (Hair et al., 1995). The fit of the mixed models was compared using the Akaike information criterion (AIC), which enables selecting among models, with lower scores indicating a more accurate fit.

\subsubsection{Balance loss analysis}

The extent to which the 10 cortical and subcortical ROIs were predictive of balance loss (vs. no balance loss) was analyzed using multilinear logistic regression (model 2). A logistic mixed model was initially tested but did not converge. The continuous variables were scaled and centered on zero. Model 2 also included vision (eyes closed vs. eyes open), weight, height, age (young vs. older adults), and total intracranial volume. Predictors were checked for the absence of multicollinearity and showed variance inflation factors below 10 (Hair et al., 1995).

The extent to which CoP RMSD was predictive of balance loss was analyzed using a logistic mixed model (model 3 ) that included both participants $(\mathrm{n}=58)$ and conditions $(\mathrm{n}=7)$ as random factors.

\subsubsection{Laterality of brain structures}

The ratio of right to left volume was calculated for each ROI to determine whether summing the bilateral structures had hidden significant predictive effects of either the right or left structure. The effect of brain structure laterality on CoP RMSD and balance loss was analyzed using linear mixed models similar to model 1 and 2 but with the bilateral volume of each ROI being replaced by the ratio of the right to left volume. As an axial structure, the brainstem was not included in these models.

\subsubsection{Mediation analysis}

Mediation analyses are used to investigate the mechanisms responsible for a relationship between 2 variables (Muller et al., 2005). Structural equation models with 10,000 bootstrap draws were used to test mediations. First, we investigated CoP RMSD as a potential mediator of the relationship between age and the number of balance loss events. Second, because brain tissues decline with age (Walhovd et al., 2011; Ziegler et al., 2012), we used a multiple mediation analysis to investigate the 10 ROIs as potential mediators of the relationship between age and postural control (CoP RMSD). Participant's height, weight, active and passive ankle ROM, total physical activity, eyes open versus eyes closed, and total gray matter volume were also included in the model as potential predictors of CoP RMSD. Mediation and multiple mediation analyses were performed using RMediation (Version 1.1.4) Lavaan (Version 0.5-20).

\subsection{Complementary analyses}

In the previously described main models, FreeSurfer automated segmentation (Fischl and Dale, 2000) was used to extract the volumetric measurement from cortical and subcortical ROIs. FreeSurfer was selected for this first step for its suitability for investigating both white and gray matter volumes (Klauschen et al., 2009).

The complementary analyses were performed to determine which subregions of the ROIs were associated with performance. Thus, to further investigate the brainstem, we selected a voxelwise analysis method, which uses a spatially unbiased atlas template of the cerebellum and brainstem (SUIT) because this method preserves the anatomical details of the brainstem to a much higher degree than the Montreal Neurological Institute (MNI) whole-brain template (Diedrichsen, 2006). To further investigate subregions of the basal ganglia, we selected the FMRIB's Integrated Registration Segmentation Toolkit (FSL FIRST), which was specifically designed to provide accurate and robust segmentation of subcortical structures such as the basal ganglia (Patenaude et al., 2011). To further investigate the middle frontal gyrus, the Voxel-Based Morphometry protocol (FSL VBM; Douaud et al., 2007; Good et al., 2001; Smith et al., 2004) with registration to the MNI152 standard space was selected because it has been demonstrated accurate for local cortical gray matter volume analysis.

\subsubsection{Voxelwise analysis of the brainstem using the SUIT high- resolution atlas template}

Because the main models showed that the brainstem was a strong predictor, we further investigated which specific subregions of the brainstem were associated with postural control. As a first preprocessing step, the anatomical MRI scan for each participant was segmented into gray matter, white matter, cerebrospinal fluid, skull, skin, and out-of-brain using SPM8. To further optimize spatial normalization of the infratentorial structures, we used the SUIT toolbox V2.7 (http://www.icn.ucl.ac.uk/motorcontrol/imaging/suit. htm; Diedrichsen, 2006; Diedrichsen et al., 2009). The images were manually cropped in MRIcron (http://www.cabiatl.com/ mricro/mricron/index.html) to remove the cerebellum and isolate the brainstem structure. The cropped images were subsequently normalized to the SUIT template using the DARTEL engine (Ashburner, 2007), whereas correcting for volume changes due to normalization (i.e., affine modulation). The resulting normalization parameters were used to reslice the white and gray matter segments for each participant into SUIT atlas space. Global brainstem volume was quantified by integrating the tissue probabilities over all voxels in the native segmented images. To avoid possible edge effects around the border between white and gray matter, we used an absolute white and gray matter threshold of $p<0.2$. To preserve precision in the definition of brainstem structure, a 4-mm default 
full width at half maximum Gaussian kernel was used for smoothing. The association between brainstem volume and postural control (CoP RMSD) was tested using a multivariate linear regression model with age group, height, and total intracranial volume as covariates. We applied an explicit brain mask to the white matter segment to include only voxels that were considered as white matter in $80 \%$ of all participants with a 0.2 probability. This analysis of the white matter segment revealed a cluster peak in the area of the pedunculopontine nucleus (see Section 3), which is a gray matter nucleus located in the predominantly white matter brainstem. Therefore, we ran the same analysis but on the gray matter segment with an explicit mask applied to include only voxels within that area (axial planes corresponding to $z=-22$ $\pm 7 \mathrm{~mm}$ ) that were considered as gray matter in $80 \%$ of all participants with a 0.2 probability. Statistical inference was performed at the cluster level (cluster defining height threshold $p<0.001$; extent threshold $=20$ voxels) on the white matter and gray matter segment, correcting for multiple comparisons over the search volume using family-wise error correction at $p<0.05$.

\subsubsection{Vertex analysis of the basal ganglia substructures using FSL FIRST}

As we expected, lower gray matter volume to be associated with greater CoP RMSD (Boisgontier et al., 2016a), and as the basal ganglia are known to be critical for movement selection and initiation in both young and older adults (Boisgontier et al., 2016b; DeLong and Wichmann, 2009), a complementary analysis was performed to further validate the positive association between basal ganglia and CoP RMSD reported in model 1 (see Section 3). Thus, the bilateral nucleus accumbens, caudate, pallidum, and putamen were segmented from the T1-weighted images using FMRIB's Integrated Registration Segmentation Toolkit (FSL FIRST; http://fsl.fmrib.ox.ac.uk/fsl/fslwiki/FIRST; Patenaude et al., 2011) in FSL Version 5.0.8 (Jenkinson et al., 2012; Smith et al., 2004; Woolrich et al., 2009). Segmented images were visually inspected in sagittal, coronal, and axial views using the FSLVIEW toolbox. Vertex analysis (FSL) was used to pinpoint the exact location of the relationship between subregional gray matter structure and postural control. The vertices represent the signed perpendicular distance from the average surface. Negative and positive values reflected inward (i.e., local contraction) and outward (i.e., local expansion) deformation of the vertices, respectively. FSL FIRST shape analysis (Patenaude et al., 2011) restricts the topology of the structures and preserves interparticipant vertex correspondence, enabling a vertex-wise comparison across individuals or conditions. Regression models using permutation-based nonparametric tests $(10,000$ draws) were applied to test the association between the CoP RMSD and the shape of the 8 basal ganglia substructures (bilateral nucleus accumbens, caudate, pallidum, and putamen) with age (young vs. older adults), height, weight, total physical activity, active ROM, passive ROM, and total intracranial volume as covariates. Significance was set at $p<0.05$, with threshold-free cluster enhancement correction for multiple comparisons (Smith and Nichols, 2009).

\subsubsection{Voxel-based morphometry of the middle frontal gyrus using FSL VBM}

Because the results on middle frontal gyrus volume were inconsistent between the linear mixed model and the structural equation model (see Section 3), a complementary analysis was performed using FSL VBM (Douaud et al., 2007; Good et al., 2001; Smith et al., 2004) to further investigate the potential association between the middle frontal gyrus and CoP RMSD. This method uses 3-dimensional magnetic resonance imaging with voxel intensity ranging from 0 to 1 to represent the combination of gray matter density and volume in each voxel. First, structural images were brain-extracted and gray-matter segmented and then registered to the MNI152 standard space using nonlinear registration. The images were then averaged to create a study-specific gray matter template. All native gray matter images were nonlinearly registered to this study-specific template and modulated to correct for local expansion or contraction of the vertices. The modulated gray matter images were then smoothed with an isotropic Gaussian kernel with a sigma of $2 \mathrm{~mm}$. Next, a mask of the middle frontal gyrus was built, based on the Harvard-Oxford cortical structural atlas. Finally, voxelwise regression models using permutationbased nonparametric tests (10,000 draws) were applied to test the association between gray matter density of the middle frontal gyrus and CoP RMSD with age group, height, and total intracranial volume as covariates. Significance was set at $p<0.05$, with threshold-free cluster enhancement correction for multiple comparisons (Smith and Nichols, 2009).

\section{Results}

\subsection{Center of pressure}

Results of model 1 (Table 1) investigating the predictors of CoP RMSD showed a significant fixed effect of brainstem $(b=-0.114$, $p=0.016)$ and basal ganglia volume $(\mathrm{b}=-0.137, p=0.004)$. To build a more parsimonious model (model 1 bis; Table 1 ) and to

Table 1

Model 1 and 1 bis: predictors of the root mean square of the center of foot pressure time series on the anteroposterior axis (RMSD)

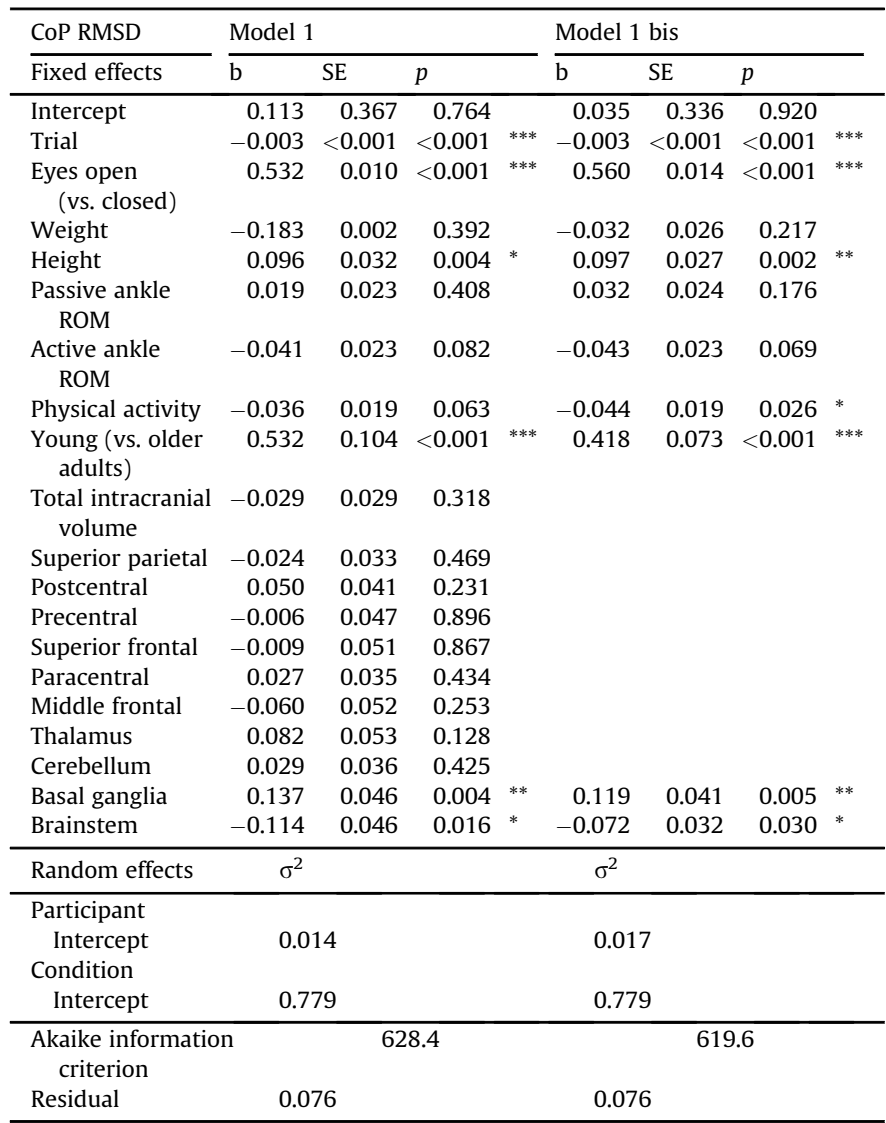

Model 1 bis predicted the data more accurately than did model 1, as indicated by a lower Akaike information criterion (AIC). ROM, range of motion, ${ }^{*} p<0.05,{ }^{* *} p<$ 0.01 , and ${ }^{* * *} p<0.001$.

Key: CoP, center of pressure; RMSD, root mean square deviation. 
confirm the sensitivity of our results, the total intracranial volume and all the ROIs identified as nonsignificant in model 1 were removed. The equation for model 1 bis is as follows:

$$
\begin{aligned}
& Y_{i j}=\left(\beta_{0}+\gamma_{0 i}+\theta_{0 j}\right)+\beta_{1} \text { Trial }_{i j}+\beta_{2} \text { Vision }_{i j}+\beta_{3} \text { Weight }_{j} \\
& +\beta_{4} \text { Height }_{\mathrm{j}}+\beta_{5} \text { Passive ROM }_{\mathrm{j}}+\beta_{6} \text { Active ROM }_{\mathrm{j}} \\
& +\beta_{7} \text { Physical Activity }_{\mathrm{j}}+\beta_{8} \text { Age Group }_{\mathrm{j}} \\
& +\beta_{9} \text { Basal Ganglia }_{\mathrm{j}}+\beta_{10} \text { Brainstem }_{\mathrm{j}}+\varepsilon_{\mathrm{ij}}
\end{aligned}
$$

where $Y_{i j}$ is the participant's score in condition $i, \beta_{0}$ to $\beta_{10}$ are the fixed effect coefficients, $\theta_{0 j}$ is the random effect for participant $j$ [random intercept], $\gamma_{0 i}$ is the random effect for condition $\mathrm{i}$ [random intercept], and $\varepsilon_{\mathrm{ij}}$ is the error term.

Model 1 bis predicted the data more accurately than model $1(\Delta$ AIC $=-8.8)$, and the effects of brainstem $(b=-0.072, p=0.030$; Fig. $3 \mathrm{~A}$ ) and basal ganglia volume $(b=0.119, p=0.005$; Fig. $3 \mathrm{~A}$ ) remained significant, confirming the robustness of the effects.

Thus, lower brainstem volume was predictive of greater CoP RMSD (i.e., poorer postural control). The complementary voxelwise analysis of the white matter segment of the brainstem showed a significant 4663-voxel cluster $(\mathrm{t}=27.88, p<0.001)$ with a peak located in the area of the pedunculopontine nucleus $(x=2 \mathrm{~mm}$, $\mathrm{y}=-29 \mathrm{~mm}$, and $\mathrm{z}=-17 \mathrm{~mm}$ [Fig. 2B] with respect to the anterior commissure [0 $\mathrm{mm}, 0 \mathrm{~mm}$, and $0 \mathrm{~mm}$ in MNI coordinates]), of which the centroid has been located at $\mathrm{x}= \pm 7 \mathrm{~mm}, \mathrm{y}=-32 \mathrm{~mm}$, $\mathrm{z}=-22 \mathrm{~mm}$ (Thevathasan et al., 2012). The analysis of the gray matter segment of the brainstem showed a 110-voxel cluster with 2 peaks $(\mathrm{x}=-2 \mathrm{~mm}, \mathrm{y}=-38 \mathrm{~mm}, \mathrm{z}=-19 \mathrm{~mm} ; \mathrm{t}=15.54, p<0.001$ and $\mathrm{x}=8 \mathrm{~mm}, \mathrm{y}=-30 \mathrm{~mm}, \mathrm{z}=-13 \mathrm{~mm}$; $\mathrm{t}=8.33, p<0.001$ ), supporting the results of the white matter segment analysis.

Unlike the brainstem, lower basal ganglia volume was predictive of lower CoP RMSD (i.e., better postural control). Results of the complementary vertex analysis showed a positive association between CoP RMSD and local expansion of the basal ganglia substructures. Thus, local expansion of the right pallidum, bilateral nucleus accumbens, and left putamen vertices (Fig. 2C) were predictive of greater CoP RMSD $(p<0.05)$ but not local caudate expansion. These results further validated the positive association between basal ganglia volume and CoP RMSD obtained with model 1 bis.

In addition to these effects of brainstem and basal ganglia volume, model 1 bis showed greater CoP RMSD (i.e., poorer postural control) in older than young adults ( $b=0.418, p<0.001$; Fig. $3 \mathrm{~A}$ ), during the eyes closed than eyes open condition $(b=0.560$, $p<0.001$; Fig. $3 A$ ), and in taller than shorter participants $(b=0.097$, $p=0.002$; Fig. 3A). Performance improved with practice across the 28 trials $(\mathrm{b}=-0.003, p<0.001 ;$ Fig. $3 \mathrm{~A})$, and total physical activity ( $\mathrm{b}=-0.044, p=0.026$; Fig. $3 \mathrm{~A}$ ) predicted better postural control. The fixed effects of weight $(b=-0.032, p=0.217)$ and of active and passive ROM $(b=-0.043$ and $0.032, p=0.069$ and 0.176 , respectively) were not significant.

Importantly, each of these effects was obtained while controlling for all the other factors in model 1 bis. Furthermore, treating both participants and conditions as random factors allowed generalizing these results not only to the population of participants but to the population of conditions as well (i.e., to other platform amplitudes and frequencies).

\subsection{Balance loss}

The percentage of balance loss events across all trials was $5.8 \%$ with 19 and 76 events in young and older adults, respectively. Results of model 2 (Table 2) investigating the odds of balance loss showed a significant fixed effect of brainstem $(b=-0.228$, $p=0.021)$ and basal ganglia volume $(b=0.224, p=0.025)$. To build a more parsimonious model (model 2 bis; Table 2) and to confirm the sensitivity of our results, the total intracranial volume and all the ROIs identified as nonsignificant in model 2 were removed. The equation for model 2 bis is as follows:

$$
\begin{aligned}
\ln \left(\pi_{x} / 1-\pi_{x}\right)= & \beta_{0}+\beta_{1} \text { Vision }+\beta_{2} \text { Weight }+\beta_{3} \text { Height } \\
& +\beta_{4} \text { Passive ROM }+\beta_{5} \text { Active ROM } \\
& +\beta_{6} \text { Physical Activity }+\beta_{7} \text { Age Group } \\
& +\beta_{8} \text { Basal Ganglia }+\beta_{9} \text { Brainstem }
\end{aligned}
$$

where $\ln \left(\pi_{x} / 1-\pi_{x}\right)$ is the log odds of losing balance, $\pi_{\mathrm{x}}$ is the probability of losing balance according to the predictors $[\mathrm{Y}=1 \mid \mathrm{x}]$, and $\beta_{0}$ to $\beta_{9}$ are the fixed effect coefficients.

Model 2 bis predicted the data more accurately than model 2 ( $\Delta$ AIC $=-12.9)$, and the effect of brainstem $(b=-0.135, p=0.032$; Fig. 3B) and basal ganglia volume $(b=0.214, p=0.008$; Fig. $3 \mathrm{~B})$ remained significant, confirming the robustness of the effects.

Model 2 bis also showed a greater number of balance loss events in older than young adults ( $b=0.740, p<0.001$; Fig. $3 B$ ), in eyes closed than eyes open condition ( $b=0.431, p<0.001$; Fig. $3 \mathrm{~B})$, in taller ( $\mathrm{b}=0.144, p=0.013$; Fig. $3 \mathrm{~B}$ ) and lighter participants $(\mathrm{b}=-0.116, p=0.024 ;$ Fig. $3 \mathrm{~B})$, and in participants with low ankle active ROM ( $b=-0.111, p=0.021$; Fig. 3B). The fixed effects of physical activity ( $\mathrm{b}=0.005, p=0.888$ ) and of passive ROM ( $b=0.008, p=0.871$ ) were not significant.

Model 3 showed a fixed effect of CoP RMSD on balance loss ( $b=0.975, p<0.001$; Table 3 ; Fig. 4), whereby greater CoP RMSD predicted more balance loss events.

\subsection{Laterality}

To investigate whether summing the bilateral structures had hidden significant predictive effects of either the right or left structure of a given ROI, the right:left volume ratios were analyzed. Results of the model testing the effect of brain structure laterality on CoP RMSD showed a significant effect of the paracentral lobule right:left ratio $(b=0.055, p=0.021)$. The other ratio effects were not significant. Accordingly, the bilateral volume of the paracentral lobule in model 1 was replaced by the volume of the right and left paracentral lobule. Results showed that the right $(b=0.058$, $p=0.061)$ and left $(b=-0.025, p=0.434)$ paracentral lobules were not predictive of CoP RMSD.

Results of the model testing the effect of brain structure laterality on balance loss showed a significant effect of the precentral gyrus right:left ratio $(b=0.125, p=0.015)$. The other ratio effects were not significant. Accordingly, the bilateral volume of the precentral gyrus in model 2 was replaced by the volume of the right and left precentral gyrus. Results showed that the right $(b=0.147$, $p=0.119)$ and left $(b=0.006, p=0.942)$ paracentral lobules were not predictive of CoP RMSD.

In sum, these laterality results revealed no additional significant predictors of CoP RMSD and balance loss to those revealed by model 1 and 2.

\subsection{Mediation}

Results of the model testing mediation of the positive relationship between aging and balance loss showed an indirect effect of CoP RMSD ( $b=0.031, p=0.032$; Fig. 5A). Results of the multiple mediation model showed an indirect effect of brainstem $(b=1.351$, $p=0.047$; Fig. 5B) and middle frontal gyrus volume $(\mathrm{b}=4.372$, $p=0.001$; Fig. 5B), whereby lower volume of these structures predicted greater CoP RMSD. The indirect effect of basal ganglia volume was also significant $(\mathrm{b}=-3.175, p=0.012)$ but in the opposite 


\section{A Center of Pressure}

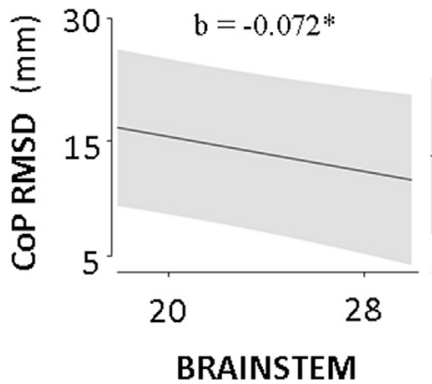

$\left(\mathrm{cm}^{3}\right)$

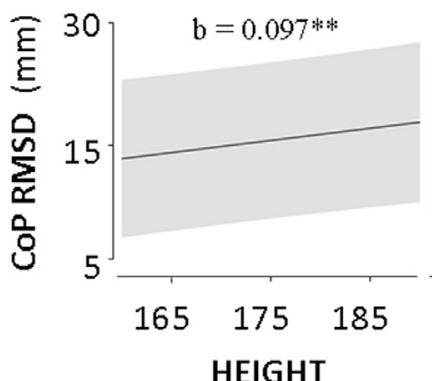

(cm)

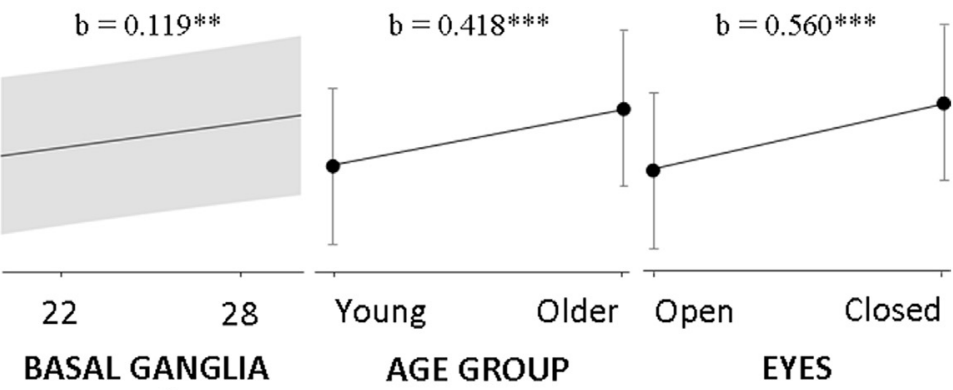

$\left(\mathrm{cm}^{3}\right)$

$\mathrm{b}=-0.003^{* * * *}$

$b=-0.044^{*}$
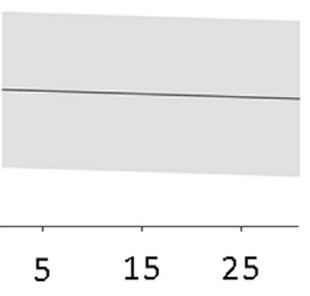

TRIAL

PHYSICAL ACTIVITY

(IPAQ total score)

\section{B Balance Loss}

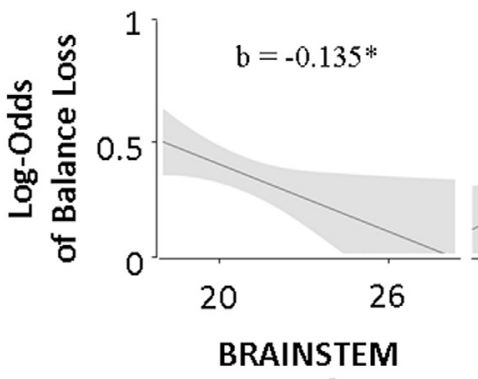

$\left(\mathrm{cm}^{3}\right)$

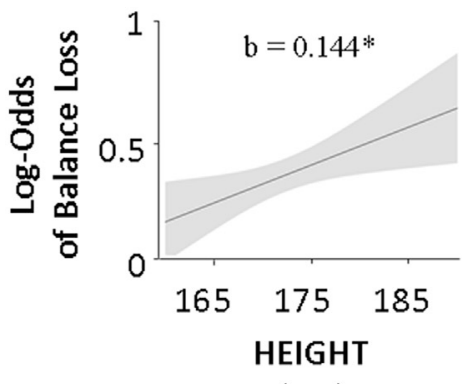

(cm)

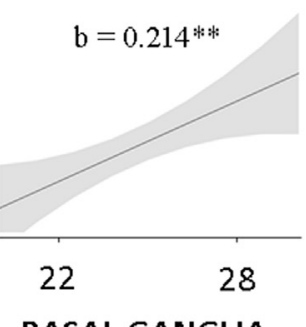

BASAL GANGLIA

$\left(\mathrm{cm}^{3}\right)$

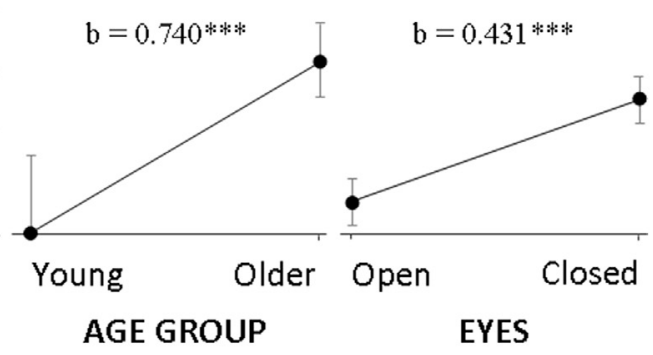

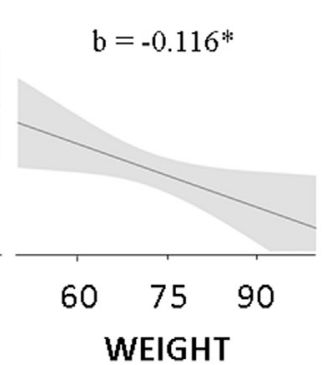

(kg)

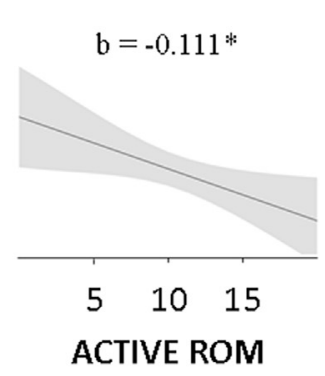

(deg)

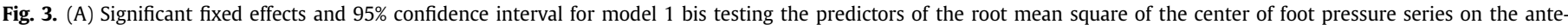

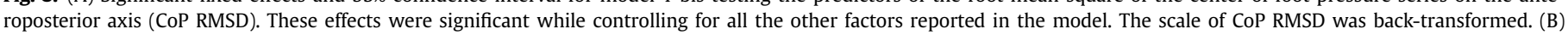

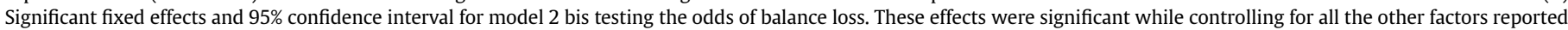
in the model. Abbreviations: CoP, center of pressure; RMSD, root mean square deviation. ${ }^{*} p<0.05,{ }^{* *} p<0.01$, and ${ }^{* * *} p<0.001$. 
Table 2

Model 2 and 2 bis: predictor of balance loss (model 2 and 2 bis)

\begin{tabular}{|c|c|c|c|c|c|c|c|c|}
\hline \multirow{2}{*}{$\frac{\text { Odds of balance loss }}{\text { Fixed effects }}$} & \multicolumn{4}{|l|}{ Model 2} & \multicolumn{4}{|l|}{ Model 2 bis } \\
\hline & $\bar{b}$ & SE & $p$ & & $\bar{b}$ & SE & $p$ & \\
\hline Intercept & $-0.327 \times 10^{0}$ & $1.189 \times 10^{-1}$ & 0.007 & *** & $-2.191 \times 10^{-1}$ & $8.304 \times 10^{-2}$ & 0.009 & $* *$ \\
\hline Eyes open (vs. closed) & $4.310 \times 10^{-1}$ & $7.181 \times 10^{-2}$ & $<0.001$ & $* * *$ & $4.310 \times 10^{-1}$ & $7.023 \times 10^{-2}$ & $<0.001$ & $* * *$ \\
\hline Weight & $-1.144 \times 10^{-1}$ & $5.980 \times 10^{-2}$ & 0.059 & & $-1.158 \times 10^{-1}$ & $5.075 \times 10^{-2}$ & 0.024 & $*$ \\
\hline Height & $1.275 \times 10^{-1}$ & $6.830 \times 10^{-2}$ & 0.065 & & $1.437 \times 10^{-1}$ & $5.683 \times 10^{-2}$ & 0.013 & $*$ \\
\hline Passive ankle ROM & $1.815 \times 10^{-2}$ & $5.149 \times 10^{-2}$ & 0.725 & & $7.656 \times 10^{-3}$ & $4.704 \times 10^{-2}$ & 0.871 & \\
\hline Active ankle ROM & $-1.242 \times 10^{-1}$ & $5.168 \times 10^{-2}$ & 0.018 & * & $-1.107 \times 10^{-1}$ & $4.711 \times 10^{-2}$ & 0.021 & $*$ \\
\hline Physical activity & $-1.825 \times 10^{-3}$ & $4.033 \times 10^{-2}$ & 0.964 & & $5.215 \times 10^{-3}$ & $3.678 \times 10^{-2}$ & 0.888 & \\
\hline Young (vs. older adults) & $9.621 \times 10^{-1}$ & $2.226 \times 10^{-1}$ & $<0.001$ & $* * *$ & $7.395 \times 10^{-1}$ & $1.379 \times 10^{-1}$ & $<0.001$ & $* * *$ \\
\hline Total intracranial volume & $-3.174 \times 10^{-2}$ & $6.155 \times 10^{-2}$ & 0.607 & & & & & \\
\hline Superior parietal & $-1.580 \times 10^{-2}$ & $6.971 \times 10^{-2}$ & 0.821 & & & & & \\
\hline Postcentral & $2.959 \times 10^{-2}$ & $8.674 \times 10^{-2}$ & 0.731 & & & & & \\
\hline Precentral & $9.471 \times 10^{-2}$ & $1.024 \times 10^{-1}$ & 0.358 & & & & & \\
\hline Superior frontal & $-7.914 \times 10^{-2}$ & $1.086 \times 10^{-1}$ & 0.468 & & & & & \\
\hline Paracentral & $-4.186 \times 10^{-2}$ & $7.375 \times 10^{-2}$ & 0.572 & & & & & \\
\hline Middle frontal & $2.727 \times 10^{-2}$ & $1.089 \times 10^{-1}$ & 0.803 & & & & & \\
\hline Thalamus & $1.108 \times 10^{-1}$ & $1.116 \times 10^{-1}$ & 0.323 & & & & & \\
\hline Cerebellum & $6.680 \times 10^{-2}$ & $7.731 \times 10^{-2}$ & 0.390 & & & & & \\
\hline Basal ganglia & $2.244 \times 10^{-1}$ & $9.820 \times 10^{-2}$ & 0.025 & $*$ & $2.144 \times 10^{-1}$ & $7.906 \times 10^{-2}$ & 0.008 & $* *$ \\
\hline Brainstem & $-2.282 \times 10^{-1}$ & $9.723 \times 10^{-2}$ & 0.021 & $*$ & $-1.353 \times 10^{-1}$ & $6.216 \times 10^{-2}$ & 0.032 & $*$ \\
\hline Akaike information criterion & & $1.283 \times 10^{2}$ & & & & $1.151 \times 10^{2}$ & & \\
\hline Residual & $1.451 \times 10^{1}$ & & & & $1.516 \times 10^{1}$ & & & \\
\hline
\end{tabular}

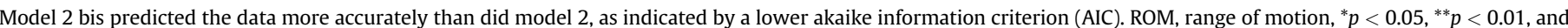
${ }^{* * *} p<0.001$

direction to the direct effect of aging on CoP RMSD $(b=9.155)$. Therefore, basal ganglia volume did not mediate the positive effect of age on CoP RMSD. The indirect effects of the other brain substructures and the total indirect effect were not significant (all $p>0.106$ ). In a sensitivity analysis, we removed all the ROIs that showed no mediation effect and retained only brainstem and middle frontal gyrus volume in the model. Results showed that the indirect effect of brainstem $(b=0.782, p=0.045)$ and middle frontal gyrus volume $(\mathrm{b}=3.889, p<0.001)$ remained significant. Taken together, these results revealed that the age-related decrease in brainstem and middle frontal volume is indirectly responsible for the age-related decrease in postural control (i.e., increased CoP RMSD), which is responsible for the age-related balance decline (Fig. 5A).

In this multiple mediation model, basal ganglia $(b=2.155$, $p=0.011)$ and brainstem volume $(b=-3.135, p<0.001)$ were positively and negatively associated with CoP RMSD, respectively. In addition, middle frontal gyrus volume was negatively associated with CoP RMSD ( $\mathrm{b}=-3.361, p<0.001$ ). However, this latter result was inconsistent with the results of the linear mixed models 1 and 1 bis. Because linear mixed models are more conservative than structural equation models (i.e., linear mixed models have fewer false positives), the significant effect of middle frontal gyrus volume obtained with the structural equation model should be interpreted with caution. Furthermore, results of the complementary voxelbased morphometry analysis supported the results of the linear mixed models, as the density of the middle frontal gyrus was not predictive of CoP RMSD (corrected $p>0.300$ ). Accordingly, brainstem volume would be the only mediator of the relationship between aging and CoP RMSD (i.e., postural control).

\section{Discussion}

In this study, we investigated the extent to which structure of cortical and subcortical brain ROIs are predictive of postural performance. Results of the main models showed that brainstem and basal ganglia volume were the strongest predictors of both postural control (CoP RMSD) and the odds of balance loss. Moreover, brainstem volume mediated the effect of aging on postural control. Results also demonstrated that postural control mediated the effect of aging on balance loss. Finally, the results showed that practice, shorter height, heavier weight, higher total physical activity, and larger ankle active (but not passive) ROM were associated with better postural performance.

\subsection{Postural control and balance}

Our results showed that the CoP displacements required to keep the vertical projection of the center of mass within the support polygon predicts the odds of balance loss. This finding supports previous results showing that $\mathrm{CoP}$ deviation was predictive of future falls in older adults (Pajala et al., 2008). Results of the mediation analysis supported and complemented these results, revealing the underlying mechanisms of this relationship with aging. Specifically, we showed that the age-related inefficiency of CoP displacements in controlling the center of mass contributed to the age-related increase in the number of balance loss events. Our results further demonstrated that reduced brainstem volume was partly responsible for this age-related decline in postural efficiency.

\subsection{Cognitive and automatic control of posture}

Our results showed that greater brainstem volume was associated with better postural stability, whereas greater basal ganglia volume showed the opposite association. These results could

Table 3

Model 3: root mean square of the center of foot pressure time series on the anteroposterior axis (RMSD) as a predictor of balance loss

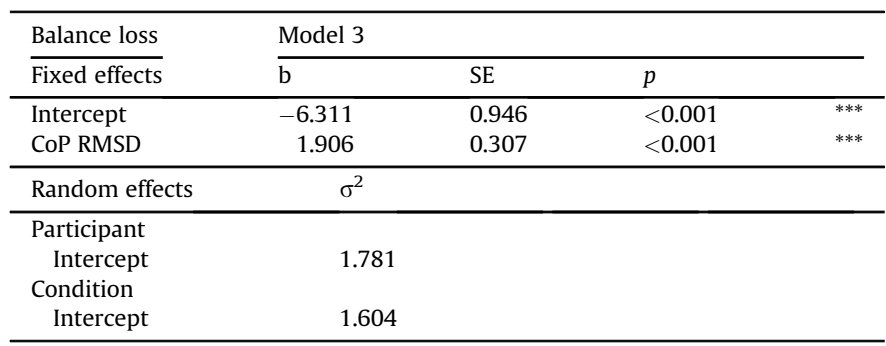

*** $p<0.001$

Key: CoP, center of pressure; RMSD, root mean square deviation. 


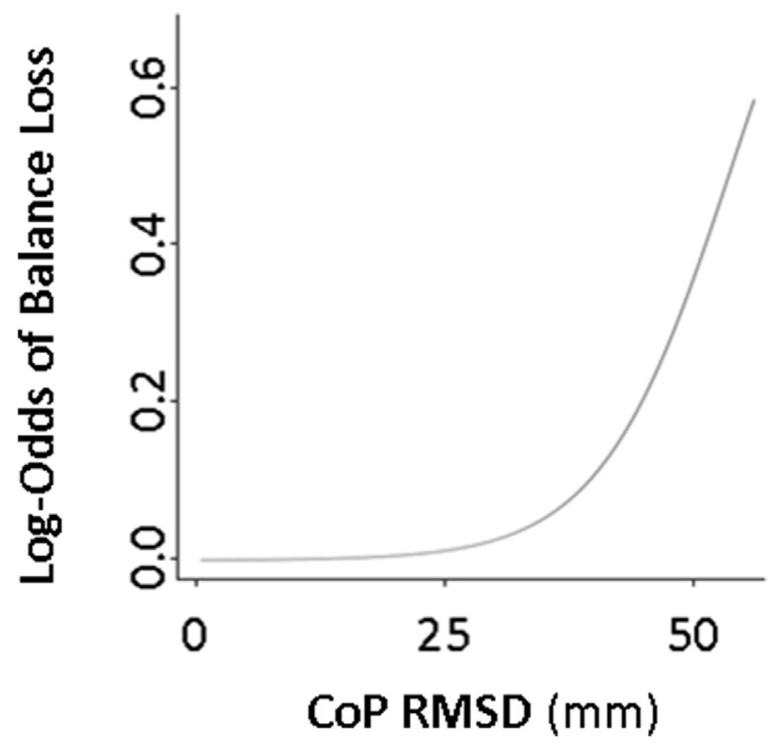

Fig. 4. Fixed effect of the root mean square of the center of foot pressure time series on the anteroposterior axis (CoP RMSD) on the odds of balance loss, as extracted from model 3. Abbreviations: CoP, center of pressure; RMSD, root mean square deviation.

possibly be explained by the notion of cognitive versus automatic postural control (Boisgontier et al., 2013), whereby postural control can be described on a continuum ranging from highly cognitively to highly automatically controlled. Thus, different levels of information processing can be distinguished, with the higher levels representing greater cognitive control and lower levels representing more automatic control (Glover, 2005). Lower levels of postural control involve more brainstem activity (Honeycutt et al., 2009), whereas higher levels of processing are assumed to involve the basal ganglia-cortical loop more (Jacobs and Horak, 2007). Higher levels involve cognitively controlled adjustments that are typically performed when an individual intend to stand as still as possible, whereas lower levels involve the automatic microadjustments that an individual performs continuously but largely unconscious. Automatic postural control was shown to be more stable than cognitive postural control, as demonstrated by shorter CoP path length (Siu and Woollacott, 2007) and lower CoP frequency responses (McNevin and Wulf, 2002; Wulf et al., 2001). Accordingly, lower neural resources involving the brainstem are expected to be associated with compromised stability, whereas higher neural resources involving the basal ganglia-cortical loop are expected to show more mixed responses, as demonstrated in this study. In patients with Parkinson's disease, which can be viewed as a model for basal ganglia dysfunction, results can be highly contradictory, showing both increased and decreased sway (Schoneburg et al., 2013). Reduced sway is sometimes associated with poor balance (Vervoort et al., 2016), which is generally related to increased stiffness and slow balance responses in these patients. In line with our results, the structure that is currently considered a major predictor of postural stability, both in Parkinson's disease (Fling et al., 2013; Lau et al., 2015; Moro et al., 2010; Welter et al., 2015) and healthy adults (Karachi et al., 2010), is the pedunculopontine nucleus in the brainstem.

\subsection{Brainstem, pedunculopontine nucleus, and fast postural responses}

We found reduced brainstem volume to be associated with poorer postural control (i.e., higher CoP RMSD) and poorer balance (i.e., higher odds balance loss). Therefore, the brainstem appears to be particularly determinant for postural stability. Studies on decerebrated cats showing appropriate muscle activation patterns in response to postural disturbances have demonstrated the involvement of the brainstem in postural balance (Honeycutt et al., 2009). For instance, the brainstem is thought to be critical for fast postural responses (Jacobs and Horak, 2007). Accordingly, recent studies have suggested that postural control and startle reflexes involve similar brainstem processes (Brown et al., 1991; Nonnekes et al., 2015). Both our white and gray matter results also suggested that the pedunculopontine nucleus is the brainstem subarea that was most strongly associated with postural stability, concurring with recent findings on the involvement of this nucleus in postural control (Lau et al., 2015). Furthermore, deep brain stimulation of the pedunculopontine nucleus area improved anticipatory postural adjustments (Welter et al., 2015) and reduced the incidence of falls 3-12 months after surgery (Moro et al., 2010; Welter et al., 2015), although other studies failed to consistently demonstrate these effects (e.g., Ferraye et al., 2010).

\subsection{Basal ganglia and movement vigor}

Our results showed an association between basal ganglia and postural performance, supporting previous clinical studies of patients with focal lesions in the basal ganglia (Visser and Bloem, 2005) and studies that found changes in basal ganglia gray matter volume as a result of postural training (Burciu et al., 2013). However, our results also showed that greater basal ganglia volume was associated with poorer stability. This was unexpected because the basal ganglia are known to be critical for movement selection and initiation in both young and older adults (Boisgontier et al., 2016b; DeLong and Wichmann, 2009). Nevertheless, this unexpected result was obtained using a method (i.e., linear mixed model) that is more stringent than traditional analyses, to prevent false positives, and was consistent across the tested dependent variables (i.e., CoP RMSD and balance loss). In addition, this result was further validated with a complementary vertex analysis of the basal ganglia substructures. Moreover, as previously mentioned for Parkinson's disease, the role of the basal ganglia in postural control and balance remains unclear (Schoneburg et al., 2013; Vervoort et al., 2016). Furthermore, acute inactivation or lesion of the basal ganglia can affect the speed or amplitude of movements without altering their selection or initiation (Desmurget and Turner, 2010; Horak and Anderson, 1984; Panigrahi et al., 2015). This association between the basal ganglia and the speed and/or amplitude of movement (i.e., vigor) was recently found in purposive actions (Dudman and Krakauer, 2016), whereby administration of levodopa into the basal ganglia ameliorates deficits in movement vigor (Panigrahi et al., 2015) and can result in premature responses in a choice reaction-time task (Economidou et al., 2012). In line with these findings, greater basal ganglia volume could be associated with more vigorous movements. However, although increased vigor is associated with better performance on purposive actions (Dudman and Krakauer, 2016), our results suggest that increased vigor may also result in exaggerated postural adjustments, thereby reducing postural stability.

\subsection{Physical activity, ankle active versus passive ROM, body mass index, and practice}

Our results showed that higher total physical activity was predictive of better postural control irrespective of age, visual condition, and postural task (static vs. dynamic). This suggests that physical activity improves the postural efficiency in keeping the center of mass within the support polygon and is consistent with 

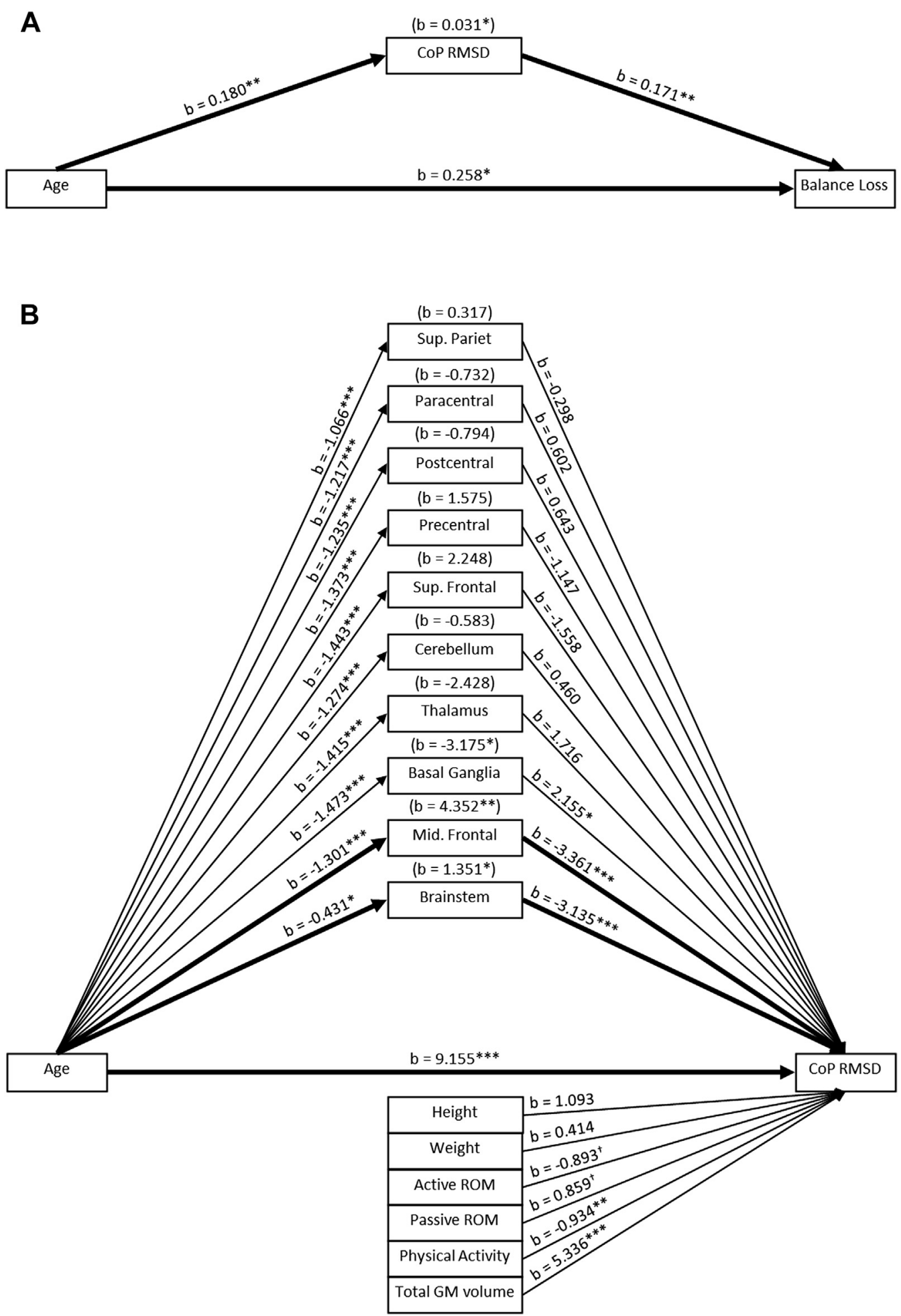

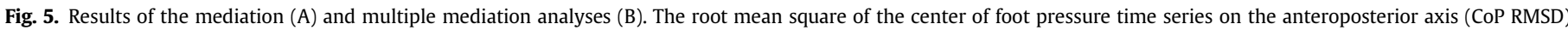

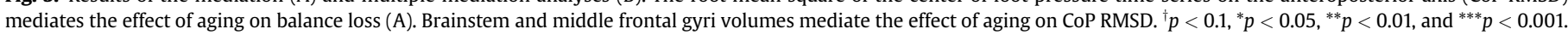
Abbreviations: CoP, center of pressure; GM, grey matter; RMSD, root mean square deviation; ROM, range of motion.

the literature that suggests similar relationships between physical activity and postural control (for a review, see Kiers et al., 2013). However, total physical activity was not predictive of balance loss.

Our results showed that taller participants had better postural control and lower odds of balance loss. In addition, heavier participants had higher odds of balance loss. Taken together, these results suggested that individuals with higher body mass index (BMI) would be less likely to fall. Indeed, when weight and height were replaced with the BMI in model 2, higher BMI was predictive of lower odds of balance loss $(b=-0.127, p=0.020)$. However, this result can be generalized to nonobese individuals only, as the mean BMI of our sample was $25 \pm 4 \mathrm{~m} \mathrm{~kg}^{-2}$. In obese individuals, 
higher BMI has been associated with poorer balance (e.g., Teasdale et al., 2007).

Our results showed that larger ankle active ROM predicted lower odds of balance loss and tended to be predictive of better postural control, whereas passive ROM was not predictive of either. Therefore, compared to passive ROM, active ROM appears to be a better predictor of postural control and balance. These results support previous findings that correlations between performance on clinical or self-reported balance tests and active ROM were generally greater than correlations with passive ROM (Mecagni et al., 2000). From our perspective, testing active ROM makes more sense than testing passive ROM because greater passive ROM may not benefit postural stability if it cannot be controlled by muscles.

Finally, our results showed that postural control improved across the 28 trials for both young and older adults, indicating a similar ability to adapt to the different conditions and/or to resist fatigue.

\section{Conclusion}

To conclude, our results revealed that (1) the brainstem structure is more critical for postural control and balance compared to the other brain structures tested here; and (2) agerelated decline in the brainstem structure partly accounts for the age-related decline in postural control. Specifically, higher neural resources in the brainstem were predictive of more efficient postural control, irrespective of age, weight, height, static versus dynamic balance conditions, task difficulty, visual condition, ankle joint mobility, and total physical activity. In other words, the brainstem appears to be fundamental for postural stability. Conversely, greater basal ganglia volume was associated with more unstable posture, which may be related to more vigorous movements. Finally, higher total physical activity, larger ankle active (but not passive) ROM, higher BMI, and practice of the postural task predicted more stable posture.

Among the strengths of the present study is the application of complementary structural imaging techniques that were carefully selected to address specific research questions. Moreover, the results were consistent across multiple dependent variables (CoP deviation, balance loss events) and multiple types of brain metrics, including volume (obtained using FreeSurfer), shape (obtained using FSL FIRST), and density (obtained using FSL VBM and SPM SUIT). Furthermore, our results were subjected to statistical analyses that limited false positive rates (i.e., linear mixed models). However, 2 potential limitations should be noted. First, the sample size was relatively small. Second, although the images were carefully inspected, acquisition and averaging of 2 T1-weighted images may have resulted in a more optimal segmentation of the images in FreeSurfer. Nevertheless, the complementary analyses using other types of imaging methods showed high consistency with the results obtained using FreeSurfer, supporting the validity of the FreeSurfer results.

\section{Disclosure statement}

The authors have no conflicts of interest to disclose.

\section{Acknowledgements}

MPB and IL are supported by a research grant (1504015N; $1514115 \mathrm{~N}$ ) and a postdoctoral fellowship from the Research Foundation-Flanders (FWO). SPS is supported by the FWO (G0721.12; G0708.14), the Interuniversity Attraction Poles Programme initiated by the Belgian Science Policy Office (P7/11), and the KU Leuven Research Fund (C16/15/070). The authors are grateful to René Clerckx for helping with data analysis. MPB and SPS contributed for experimental conception. MPB contributed for experimental design. MPB conducted the experiment. MPB and OL performed the analysis of postural data. MPB, SC, PVR, IL contributed for the analysis of imaging data. MPB and BC contributed for statistical analysis. MPB prepared the first draft. MPB, BC, SC, PVR, IL, OL, AN, and SPS contributed for manuscript preparation.

\section{References}

Alonso, A.C., Mochizuki, L., Silva Luna, N.M., Ayama, S., Canonica, A.C., Greve, J.M., 2015. Relation between the sensory and anthropometric variables in the quiet standing postural control: is the inverted pendulum important for the static balance control? Biomed. Res. Int. 2015, 985312.

Andersen, B.B., Gundersen, H.J., Pakkenberg, B., 2003. Aging of the human cerebellum: a stereological study. J. Comp. Neurol. 466, 356-365.

Ashburner, J., 2007. A fast diffeomorphic image registration algorithm. Neuroimage 38, 95-113.

Bloss, E.B. Janssen, W.G. Ohm, D.T, Yuk, FJ. Wadsworth, S., Saardi, K.M. McEwen, B.S., Morrison, J.H., 2011. Evidence for reduced experience-dependent dendritic spine plasticity in the aging prefrontal cortex. Neurosci. 31, 7831-7839.

Boisgontier, M.P., 2015. Motor aging results from cerebellar neuron death. Trends Neurosci. 38, 127-128.

Boisgontier, M.P., Beets, I.A.M., Duysens, J., Nieuwboer, A., Krampe, R.T. Swinnen, S.P., 2013. Age-related differences in attentional cost associated with postural dual tasks: increased recruitment of generic cognitive resources in older adults. Neurosci. Biobehav. Rev. 37, 1824-1837.

Boisgontier, M.P., Cheval, B., 2016. The anova to mixed model transition. Neurosci Biobehav. Rev. 68, 1004-1005.

Boisgontier, M.P., Cheval, B., van Ruitenbeek, P., Levin, O., Renaud, O., Chanal, C. Swinnen, S.P., 2016a. Whole-brain grey matter density predicts balance stability irrespective of age and protects older adults from falling. Gait Posture 45, 143-150.

Boisgontier, M.P., van Ruitenbeek, P., Leunissen, I., Chalavi, S., Sunaert, S., Levin, O. Swinnen, S.P., 2016b. Nucleus accumbens and caudate atrophy predicts longer action selection times in young and older adults. Hum. Brain Mapp. 37, 4629-4639.

Box, G.E.P., Cox, D.R., 1964. An analysis of transformations. J. R. Stat. Soc. Ser. B Stat. Methodol. 26, 211-252.

Brown, P., Rothwell, J.C., Thompson, P.D., Britton, T.C., Day, B.L., Marsden, C.D., 1991. New observations on the normal auditory startle reflex in man. Brain 114, 1891-1902.

Burciu, R.G., Fritsche, N., Granert, O., Schmitz, L., Spönemann, N., Konczak, J. Theysohn, N., Gerwig, M., van Eimeren, T., Timmann, D., 2013. Brain changes associated with postural training in patients with cerebellar degeneration: a voxel-based morphometry study. J. Neurosci. 33, 4594-4604.

Colby, S.L., Ortman, J.M., 2015. Projections of the size and composition of the U.S population: 2014 to 2060. Curr. Popul. Rep. 25, 1143.

Corso, P., Finkelstein, E., Miller, T., Fiebelkorn, I., Zaloshnja, E., 2015. Incidence and lifetime costs of injuries in the United States. Inj. Prev. 21, 434-440.

Craig, C.L., Marshall, A.L., Sjostrom, M., Bauman, A.E., Booth, M.L., Ainsworth, B.E., Pratt, M., Ekelund, U., Yngve, A., Sallis, J.F., Oja, P., 2003. International physical activity questionnaire: 12-country reliability and validity. Med. Sci. Sports Exerc. 35, 1381-1395.

Dale, A.M., Fischl, B., Sereno, M.I., 1999. Cortical surface-based analysis. I. Segmentation and surface reconstruction. Neuroimage 9, 179-194.

DeLong, M., Wichmann, T., 2009. Update on models of basal ganglia function and dysfunction. Parkinsonism Relat. Disord. 15, S237-S240.

de Oliveira, J.M., 2016. Statokinesigram normalization method. Behav. Res. Methods http://dx.doi.org/10.3758/s13428-016-0706-4.

Desmurget, M., Turner, R.S., 2010. Motor sequences and the basal ganglia: kinematics, not habits. J. Neurosci. 30, 7685-7690.

Diedrichsen, J., 2006. A spatially unbiased atlas template of the human cerebellum. Neuroimage 33, 127-138.

Diedrichsen, J., Balsters, J.H., Flavell, J., Cussans, E., Ramnani, N., 2009. A probabilistic MR atlas of the human cerebellum. Neuroimage 46, 39-46.

Douaud, G., Smith, S., Jenkinson, M., Behrens, T., Johansen-Berg, H., Vickers, J., James, S., Voets, N., Watkins, K., Matthews, P.M., James, A., 2007. Anatomically related grey and white matter abnormalities in adolescent-onset schizophrenia. Brain 130, 2375-2386.

Drijkoningen, D., Leunissen, I., Caeyenberghs, K., Hoogkamer, W., Sunaert, S. Duysens, J., Swinnen, S.P., 2015. Regional volumes in brain stem and cerebellum are associated with postural impairments in young brain-injured patients. Hum. Brain Mapp. 36, 4897-4909.

Dudman, J.T., Krakauer, J.W., 2016. The basal ganglia: from motor commands to the control of vigor. Curr. Opin. Neurobiol. 37, 158-166.

Economidou, D., Theobald, D.E., Robbins, T.W., Everitt, B.J., Dalley, J.W., 2012 Norepinephrine and dopamine modulate impulsivity on the five-choice serial reaction time task through opponent actions in the shell and core sub-regions of the nucleus accumbens. Neuropsychopharmacology 37, 2057-2066.

Eklund, A., Nichols, T.E., Knutsson, H., 2016. Cluster failure: why fMRI inferences for spatial extent have inflated false-positive rates. Proc. Natl. Acad. Sci. U. S. A. 113, 7900-7905.

Elveru, R.A., Rothstein, J.M., Lamb, R.L., 1988. Goniometric reliability in a clinical setting. Subtalar and ankle joint measurements. Phys. Ther. 68, 672-677.

Ferraye, M.U., Debû, B., Fraix, V., Goetz, L., Ardouin, C., Yelnik, J., Henry-Lagrange, C., Seigneuret, E., Piallat, B., Krack, P., Le Bas, J.F., Benabid, A.L., Chabardès, S. 
Pollak, P., 2010. Effects of pedunculopontine nucleus area stimulation on gait disorders in Parkinson's disease. Brain 133, 205-214.

Fischl, B., Dale, A.M., 2000. Measuring the thickness of the human cerebral cortex from magnetic resonance images. Proc. Natl. Acad. Sci. U. S. A. 97, 11050-11055.

Fischl, B., Salat, D.H., van der Kouwe, A.J., Makris, N., Ségonne, F., Quinn, B.T., Dale, A.M., 2004. Sequence-independent segmentation of magnetic resonance images. Neuroimage 23, S69-S84.

Fling, B.W., Cohen, R.G., Mancini, M., Nutt, J.G., Fair, D.A., Horak, F.B., 2013. Asymmetric pedunculopontine network connectivity in parkinsonian patients with freezing of gait. Brain 136, 2405-2418.

Gelbard, R., Inaba, K., Okoye, O.T., Morrell, M., Saadi, Z., Lam, L., Talving, P., Demetriades, D., 2014. Falls in the elderly: a modern look at an old problem. Am. J. Surg. 208, 249-253.

Glover, S., 2005. A hierarchical model of the cognitive penetrability of actions. In: Raftopoulos, A. (Ed.), Cognitive Penetrability of Perception. Nova Science Publishers, New York, pp. 193-208.

Goble, D.J., Coxon, J.P., Van Impe, A., Geurts, M., Doumas, M. Wenderoth, N. Swinnen, S.P., 2011. Brain activity during ankle proprioceptive stimulation predicts balance performance in young and older adults. J. Neurosci. 31, 16344-16352.

Goble, D.J., Coxon, J.P., Van Impe, A., Geurts, M., Van Hecke, W., Sunaert, S., Wenderoth, N., Swinnen, S.P., 2012. The neural basis of central proprioceptive processing in older versus younger adults: an important sensory role for right putamen. Hum. Brain Mapp. 33, 895-908.

Good, C.D., Johnsrude, I.S., Ashburner, J., Henson, R.N., Friston, K.J., Frackowiak, R.S., 2001. A voxel-based morphometric study of ageing in 465 normal adult human brains. Neuroimage 14, 21-36.

Hair Jr., J.F., Anderson, R.E., Tatham, R.L., Black, W.C., 1995. Multivariate Data Analysis, third ed. Macmillan, New York.

Heijnen, M.J., Rietdyk, S., 2016. Falls in young adults: perceived causes and environmental factors assessed with a daily online survey. Hum. Mov. Sci. 46, 86-95.

Honeycutt, C.F., Gottschall, J.S., Nichols, T.R., 2009. Electromyographic responses from the hindlimb muscles of the decerebrate cat to horizontal support surface perturbations. J. Neurophysiol. 101, 2751-2761.

Horak, F.B., Anderson, M.E., 1984. Influence of globus pallidus on arm movements in monkeys. I. Effects of kainic acid-induced lesions. J. Neurophysiol. 52, 290-304.

Horak, F.B., Diener, H.C., 1994. Cerebellar control of postural scaling and central set in stance. J. Neurophysiol. 72, 479-493.

Jacobs, J.V., Horak, F.B., 2007. Cortical control of postural responses. J. Neural Transm. 114, 1339-1348.

Jellema, T., Maassen, G., Perrett, D.I., 2004. Single cell integration of animate form, motion and location in the superior temporal cortex of the macaque monkey. Cereb. Cortex 14, 781-790.

Jenkinson, M., Beckmann, C.F., Behrens, T.E., Woolrich, M.W., Smith, S.M., 2012. FSL, NeuroImage 62, 782-790.

Karachi, C., Grabli, D., Bernard, F.A., Tandé, D., Wattiez, N., Belaid, H., Bardinet, E., Prigent, A., Nothacker, H.P., Hunot, S., Hartmann, A., Lehéricy, S., Hirsch, E.C., François, C., 2010. Cholinergic mesencephalic neurons are involved in gait and postural disorders in Parkinson disease. J. Clin. Invest. 120, 2745-2754.

Karnath, H.O., Ferber, S., Dichgans, J., 2000. The neural representation of postural control in humans. Proc. Natl. Acad. Sci. U. S. A. 97, 13931-13936.

Kennedy, R.L., Grant, P.T., Blackwell, D., 2001. Low-impact falls: demands on a system of trauma management, prediction of outcome, and influence of comorbidities. J. Trauma 51, 717-724.

Kiers, H., van Dieën, J., Dekkers, H., Wittink, H., Vanhees, L., 2013. A systematic review of the relationship between physical activities in sports or daily life and postural sway in upright stance. Sports Med. 43, 1171-1189.

Klauschen, F., Goldman, A., Barra, V., Meyer-Lindenberg, A., Lundervold, A., 2009. Evaluation of automated brain MR image segmentation and volumetry methods. Hum. Brain Mapp. 30, 1310-1327.

Konor, M.M., Morton, S., Eckerson, J.M., Grindstaff, T.L., 2012. Reliability of three measures of ankle dorsiflexion range of motion. Int. J. Sports Phys. Ther. 7, 279-287.

Lau, B., Welter, M.L., Belaid, H., Fernandez Vidal, S., Bardinet, E., Grabli, D., Karachi, C., 2015. The integrative role of the pedunculopontine nucleus in human gait. Brain 138, 1284-1296.

McNevin, N.H., Wulf, G., 2002. Attentional focus on supra-postural tasks affects postural control. Hum. Mov. Sci. 21, 187-202.

Mecagni, C., Smith, J.P., Roberts, K.E., O'Sullivan, S.B., 2000. Balance and ankle range of motion in community-dwelling women aged 64 to 87 years: a correlational study. Phys. Ther. 80, 1004-1011.

Mihara, M., Miyai, I., Hatakenaka, M., Kubota, K., Sakoda, S., 2008. Role of the prefrontal cortex in human balance control. Neuroimage 43, 329-336.

Moro, E., Hamani, C., Poon, Y.Y., Al-Khairallah, T., Dostrovsky, J.O., Hutchison, W.D., Lozano, A.M., 2010. Unilateral pedunculopontine stimulation improves falls in Parkinson's disease. Brain 133, 215-224.

Morton, S.M., Bastian, A.J., 2004. Cerebellar control of balance and locomotion. Neuroscientist 10, 247-259.

Muller, D., Judd, C.M., Yzerbyt, V.Y., 2005. When moderation is mediated and mediation is moderated. J. Pers. Soc. Psychol. 89, 852-863.

Nonnekes, J., Carpenter, M.G., Inglis, J.T., Duysens, J., Weerdesteyn, V., 2015. What startles tell us about control of posture and gait. Neurosci. Biobehav. Rev. 53, 131-138.

Norkin, C.C., White, D.J., 1995. Measurement of Joint Motion: A Guide to Goniometry, second ed. FA Davis Co, Philadelphia.
Osborne, J.W., 2010. Improving your data transformations: applying the Box-Cox transformation. Pract. Assess. Res. Eval. 15, 1-9.

Ouchi, Y., Okada, H., Yoshikawa, E., Nobezawa, S., Futatsubashi, M., 1999. Brain activation during maintenance of standing postures in humans. Brain 122 $329-338$

Pajala, S., Era, P., Koskenvuo, M., Kaprio, J., Törmäkangas, T., Rantanen, T., 2008. Force platform balance measures as predictors of indoor and outdoor falls in community-dwelling women aged 63-76 years. J. Gerontol. A. Biol. Sci. Med. Sci. $63,171-178$.

Panigrahi, B., Martin, K.A., Li, Y., Graves, A.R., Vollmer, A., Olson, L., Mensh, B.D., Karpova, A.Y., Dudman, J.T., 2015. Dopamine is required for the neural representation and control of movement vigor. Cell 162, 1418-1430.

Panizzon, M.S., Fennema-Notestine, C., Eyler, L.T., Jernigan, T.L., Prom-Wormley, E., Neale, M., Jacobson, K., Lyons, M.J., Grant, M.D., Franz, C.E., Xian, H, Tsuang, M., Fischl, B., Seidman, L., Dale, A., Kremen, W.S., 2009. Distinct genetic influences on cortical surface area and cortical thickness. Cereb. Cortex 19, 2728-2735.

Patenaude, B., Smith, S.M., Kennedy, D.N., Jenkinson, M., 2011. A Bayesian model of shape and appearance for subcortical brain segmentation. Neuroimage 56, 907-922.

Pellijeff, A., Bonilha, L., Morgan, P.S., McKenzie, K., Jackson, S.R., 2006. Parietal updating of limb posture: an event-related fMRI study. Neuropsychologia 44 2685-2690.

Qing, Z., Gong, G., 2016. Size matters to function: brain volume correlates with intrinsic brain activity across healthy individuals. Neuroimage 139, 271-278.

Schoneburg, B., Mancini, M., Horak, F., Nutt, J.G., 2013. Framework for understanding balance dysfunction in Parkinson's disease. Mov. Disord. 28, 1474-1482.

Shumway-Cook, A., Woollacott, M.H., 2007. Motor Control: Translating Research into Clinical Practice, third ed. Lippincott Williams \& Wilkins, Philadelphia.

Siu, K.C., Woollacott, M.H., 2007. Attentional demands of postural control: the ability to selectively allocate information-processing resources. Gait Posture 25 $121-126$.

Slobounov, S., Hallett, M., Stanhope, S., Shibasaki, H., 2005. Role of cerebral cortex in human postural control: an EEG study. Clin. Neurophysiol. 116, 315-323.

Slobounov, S., Wu, T. Hallett, M., 2006. Neural basis subserving the detection of postural instability: an fMRI study. Motor Control 10, 69-89.

Smith, S.M., Jenkinson, M., Woolrich, M.W., Beckmann, C.F., Behrens, T.E.J. Johansen-Berg, H., Bannister, P.R., De Luca, M., Drobnjak, I., Flitney, D.E. Niazy, R., Saunders, J., Vickers, J., Zhang, Y., De Stefano, N., Brady, J.M., Matthews, P.M., 2004. Advances in functional and structural MR image analysis and implementation as FSL. Neuroimage 23, S208-S219.

Smith, S.M., Nichols, T.E., 2009. Threshold-free cluster enhancement: addressing problems of smoothing, threshold dependence and localisation in cluster inference. Neuroimage 44, 83-98.

Stevens, J.A., Corso, P.S., Finkelstein, E.A., Miller, T.R., 2006. The costs of fatal and non-fatal falls among older adults. Inj. Prev. 12, 290-295.

Taubert, M., Mehnert, J., Pleger, B., Villringer, A., 2016. Rapid and specific grey matter changes in M1 induced by balance training. Neuroimage 133, 399-407.

Teasdale, N., Hue, O., Marcotte, J., Berrigan, F., Simoneau, M., Doré, J., Marceau, P., Marceau, S., Tremblay, A., 2007. Reducing weight increases postural stability in obese and morbid obese men. Int. J. Obes. (Lond.) 31, 153-160.

Thevathasan, W., Cole, M.H., Graepel, C.L., Hyam, J.A., Jenkinson, N., Brittain, J.S. Coyne, T.J., Silburn, P.A., Aziz, T.Z., Kerr, G., Brown, P., 2012. A spatiotemporal analysis of gait freezing and the impact of pedunculopontine nucleus stimulation. Brain 135, 1446-1454.

Tinetti, M.E., Williams, C.S., 1997. Falls, injuries due to falls, and the risk of admission to a nursing home. N. Engl. J. Med. 337, 1279-1284.

Vangeneugden, J., De Mazière, P.A., Van Hulle, M.M., Jaeggli, T., Van Gool, L., Vogels, R., 2011. Distinct mechanisms for coding of visual actions in macaque temporal cortex. J. Neurosci. 31, 385-401.

Vervoort, G., Bengevoord, A., Strouwen, C., Bekkers, E.M., Heremans, E. Vandenberghe, W., Nieuwboer, A., 2016. Progression of postural control and gait deficits in Parkinson's disease and freezing of gait: a longitudinal study. Parkinsonism Relat. Disord. 28, 73-79.

Visser, J.E., Bloem, B.R., 2005. Role of the basal ganglia in balance control. Neural Plast. 12, 161-174.

Walhovd, K.B., Westlye, L.T., Amlien, I., Espeseth, T., Reinvang, I., Raz, N., Agartz, I. Sa-lat, D.H., Greve, D.N., Fischl, B., Dale, A.M., Fjell, A.M., 2011. Consisten neuroana-tomical age-related volume differences across multiple samples. Neurobiol. Aging 32, 916-932.

Welter, M.L., Demain, A., Ewenczyk, C., Czernecki, V., Lau, B., El Helou, A., Belaid, H. Yelnik, J., François, C., Bardinet, E., Karachi, C., Grabli, D., 2015. PPNa-DBS for gait and balance disorders in Parkinson's disease: a double-blind, randomised study. J. Neurol. 262, 1515-1525.

Woolrich, M.W., Jbabdi, S., Patenaude, B., Chappell, M., Makni, S., Behrens, T. Beckmann, C., Jenkinson, M., Smith, S.M., 2009. Bayesian analysis of neuroimaging data in FSL. Neuroimage 45, S173-S186.

Wulf, G., McNevin, N., Shea, C.H., 2001. The automaticity of complex motor skill learning as a function of attentional focus. Q. J. Exp. Psychol. A 54 1143-1154.

Youdas, J.W., Bogard, C.L., Suman, V.J., 1993. Reliability of goniometric measurements and visual estimates of ankle joint active range of motion obtained in a clinical setting. Arch. Phys. Med. Rehabil. 74, 1113-1118.

Ziegler, G., Dahnke, R., Jäncke, L., Yotter, R.A., May, A., Gaser, C., 2012. Brain structural trajectories over the adult lifespan. Hum. Brain Mapp. 33, 2377-2389. 